\title{
Modelling of Suspended Particulate Matter in Silence Zone in a Cosmopolitan City
}

\author{
Dr. Umesh Sharma ${ }^{1}$, Dr. S.N. Sachdeva ${ }^{2}$ and Dr. Siby John ${ }^{3}$
}

\begin{abstract}
The source of Suspended Particulate Matter (SPM) can be manmade or natural. Industrial expansion, vehicular traffic, exhaust of thermal power plants and municipal waste incinerators are the few illustrations of manmade source; whereas volcanoes and dust storms are natural sources. In the last few decades cities enlargement, increase of urban activities, improvement of technology, rising of families' income, easy availability of loan and lowering of automobile prices sources the striking increase of automobile numbers in urban areas making vehicular emission as one of the prime source of Pollution/Particulate matter. The level of lead increases with the increase of traffic density since tetraethyl lead is added as an anti-knock to the petroleum fuel being used in automobiles. It has been acclaimed worldwide that the gases from burning fuels react with sunlight and presence of water vapour increases the concentration of SPM. Consequently, it results in aggravated asthma, increase in respiratory problems, chronic bronchitis, decreased lung function or may be premature death. The same is taking place in Chandigarh - An Indian city beautiful which is not only world famous for its unique architecture and imaginative planning, but also for its emergence as a major centre for educational, sports and cultural activities. In the Present work the suspended particulate matter with respect to the vehicular Traffic has been determined and a statistical model correlating the various parameters have been developed, which will help the traffic planners to ensure the effective Traffic Management.
\end{abstract}

Keywords----Particulate Matter, Silence Zone, Cosmopolitan City

\section{INTRODUCTION}

A compelling reason for controlling air pollutants such as suspended particulate matter (SPM) or respirable particulate matters (RPM) or sulphur dioxide $\left(\mathrm{SO}_{2}\right)$ is their damaging effect on human health. These effects include mortality i.e., premature death as well as morbidity i.e., increases in the incidence of chronic heart and lung disease. According to the World Health Organization (WHO), 4 to $8 \%$ of deaths that occur annually in the world are related to air pollution. Of all air pollution constituents, the WHO has identified SPM as the most sinister in terms of its effect on health [1].

Transport sector is the key element in infrastructure as it provides services essential for promoting development and plays a significant role in influencing the pattern of distribution of economic activity along with production improvement. The

Manuscript received July. 2, 2016.

${ }^{1}$ Dr. Umesh Sharma is associate professor, Civil Engineering Department at PEC University of Technology, Chandigarh, India .

${ }^{2}$ Dr. S.N Sachdeva is Professor, Civil Engineering Department at National Institute of Technology, Kurukshetra, India.

${ }^{3}$ Dr. Siby John is Professor and Head of Department, Civil Engineering Department at PEC University of Technology, Chandigarh, India. increased travel demand has resulted in rapid growth in the number of motor vehicles in the cities. Vehicle ownership in cities has increased with rising household income, aspirations for better quality of life, enabling a market environment for vehicle purchase, increasing trip lengths and inadequate public transport system. The heavy concentration of private motor vehicles in cosmopolitan cities has been one of the key reasons for congestion, increased travel times, accidents and pollution (SPM). Air pollution from motor vehicles is one of the most serious and rapidly growing problems in the cities. Vehicular emissions are the principal contributor of air pollution, a rowing menace which needs to be contained [2].

The Air prevention act, 1981 (Air act) is an important legislative measure aimed at prevention and control of air pollution in India. Under which, Central Pollution Control Board had notified the following National Ambient Air Quality Standards for SPM as given in Table 1[3].

TABLE 1: NAAQS FOR STANDARD PARTICULATE MATTER

\begin{tabular}{|c|c|c|c|c|}
\hline \multirow{2}{*}{ Pollutant } & \multirow{2}{*}{$\begin{array}{c}\text { Time } \\
\text { Weighted } \\
\text { Average }\end{array}$} & (1) & \multicolumn{2}{|c|}{ Time weighted average } \\
\hline & & $\begin{array}{r}\text { Indust } \\
\text { rial Area }\end{array}$ & $\begin{array}{c}\text { Residen } \\
\text { tial Area }\end{array}$ & $\begin{array}{r}\text { Sensiti } \\
\text { ve Area }\end{array}$ \\
\hline \multirow{2}{*}{$\begin{array}{c}\text { Suspended } \\
\text { Particulate } \\
\text { Matter (SPM) }\end{array}$} & $\begin{array}{c}\text { Annual } \\
\text { average* }\end{array}$ & $\begin{array}{l}360 \mu \mathrm{g} / \\
\mathrm{m}^{3}\end{array}$ & $\begin{array}{l}140 \mu \mathrm{g} / \\
\mathrm{m}^{3}\end{array}$ & $\begin{array}{l}70 \mu \mathrm{g} / \\
\mathrm{m}^{3}\end{array}$ \\
\hline & 24 hours $* *$ & $\begin{array}{l}500 \mu \mathrm{g} / \\
\mathrm{m}^{3}\end{array}$ & $\begin{array}{l}200 \mu \mathrm{g} / \\
\mathrm{m}^{3}\end{array}$ & $\begin{array}{l}100 \mu \mathrm{g} / \\
\mathrm{m}^{3}\end{array}$ \\
\hline
\end{tabular}

*Annual arithmetic mean of minimum 104 measurements in a year taken twice a week 24 hourly at uniform interval.

**24hourly/8hourly values should be met $98 \%$ of the time in a year. However, $2 \%$ of the time it may exceed but not on two consecutive days.

In this paper, statistical analysis has been done, to formulate the regression equation between traffic volume and SPM. The model will help the traffic managers and environmental boards to plan the policies in an effective manner.

\section{MATERIALS AND MethodS}

\section{A. Study Area}

Chandigarh which is known as "The City Beautiful" was designed by the famous architect Le Corbusier and is a first planned city of India. It is capital of two states i.e. Punjab and Haryana and is situated at a distance of $256 \mathrm{kms}$ North of Delhi at the base of Shivalik Hills of outer Himalayas. Its notion is based on the necessities of human beings, namely living, 
working, core of body, spirit and circulation: The three main functional elements of the city; capital complex, city centre and the university have been located in the three different corners of the city, connected by a large linear park containing here and there some special cultural and educational buildings. Road system in Chandigarh as shown in fig. 1 has a grid iron pattern with principal corridors like Madhya Marg, Lok Path, Himalaya Marg, Uttar Marg etc. Similar to other popular cities, the population of Chandigarh has also increased from about 5 lacs in 1981 to about 14 lacs in 2014, resulting $n$ increase in vehicular population from about 0.60 Lacs to about 12 lacs, on a total road length of $1458 \mathrm{kms}$.

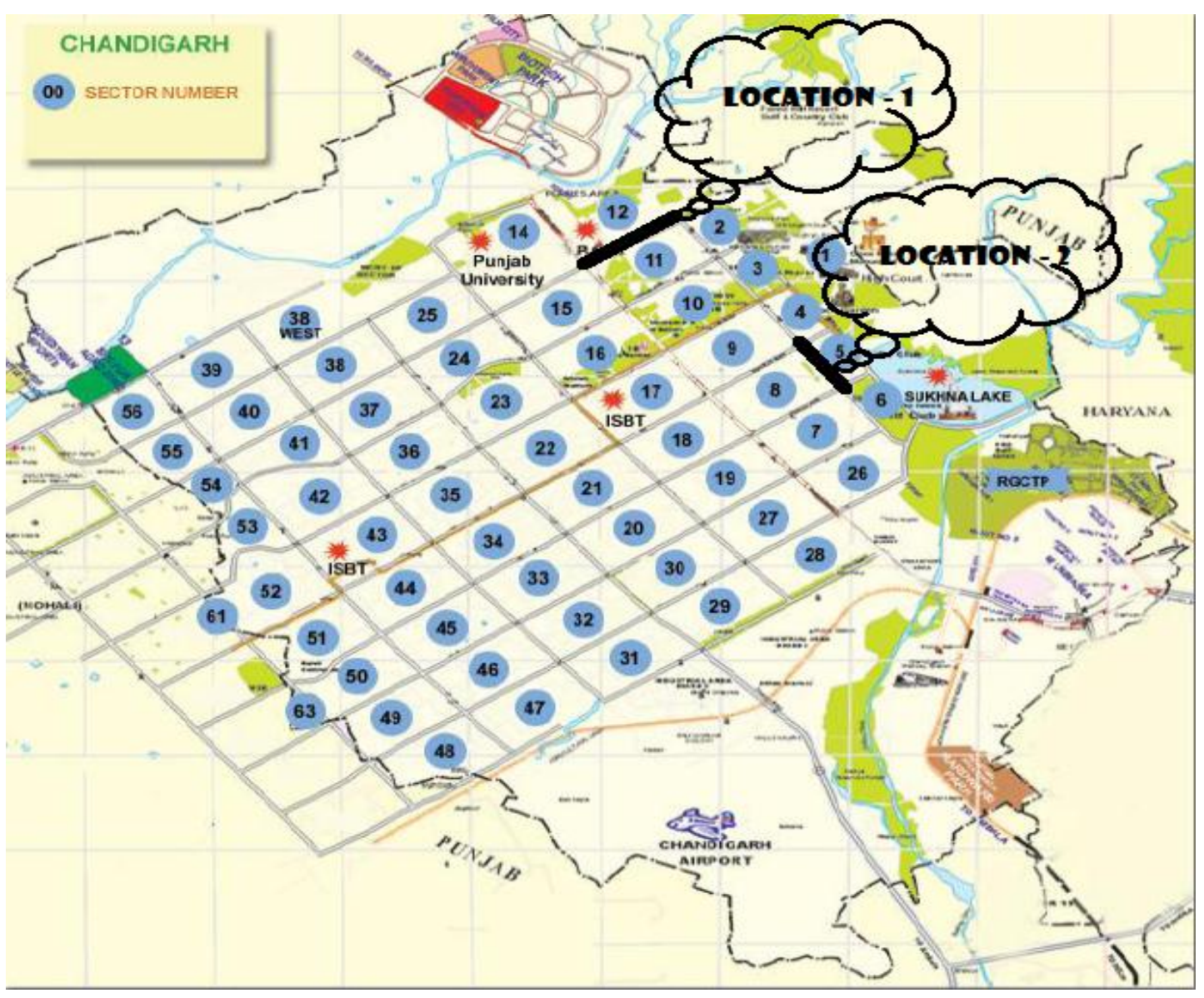

Fig. 1. Map of Chandigarh

For study, two sections from two different roads i.e. Vigyan path (in front of PGI) and Uttar Marg (road between Governor's House and Secretariat) were taken into consideration, as these sections drop under the routes of silence zone.

\section{A. Data Collection}

The collection of data was done in two stages i.e. traffic data and SPM determination.

The traffic on the Chandigarh Roads is found to be of heterogeneous nature. The heterogeneous nature of traffic was normalized by converting the number of different types of vehicles, into equivalent passenger car units (PCUs) by using equivalency factors as prescribed by IRC [4]. The flow is then expressed as PCUs per hour. The traffic study was conducted for 10 hours at different locations using manual count method and the peak flow timings were noted. The variation traffic volume (PCU/Hr) versus Time of the day is shown in the graphical form in fig. - 2 for both $\mathrm{ON}$ and OFF days.

SPM determination: The concentration of S.P.M was determined by using the procedure prescribed by Indian Standards (IS 5182 (Part 4) 1999) [3]. The Whatman's GF/A grade filter paper were used. The gravimetric measurements were made upto an accuracy of $0.1 \mathrm{mg}$. the details of variation are SPM $\left(\mu \mathrm{g} / \mathrm{m}^{3}\right)$ with respect to time are shown in fig. -2 .

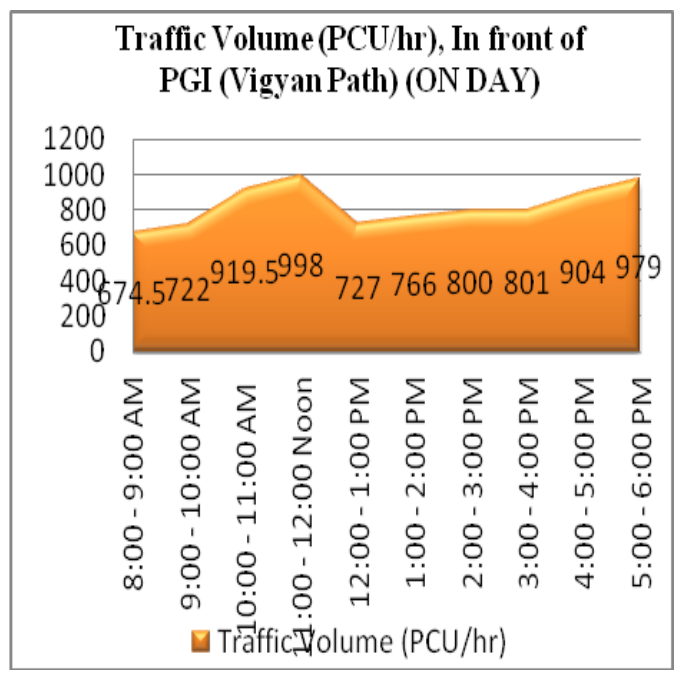




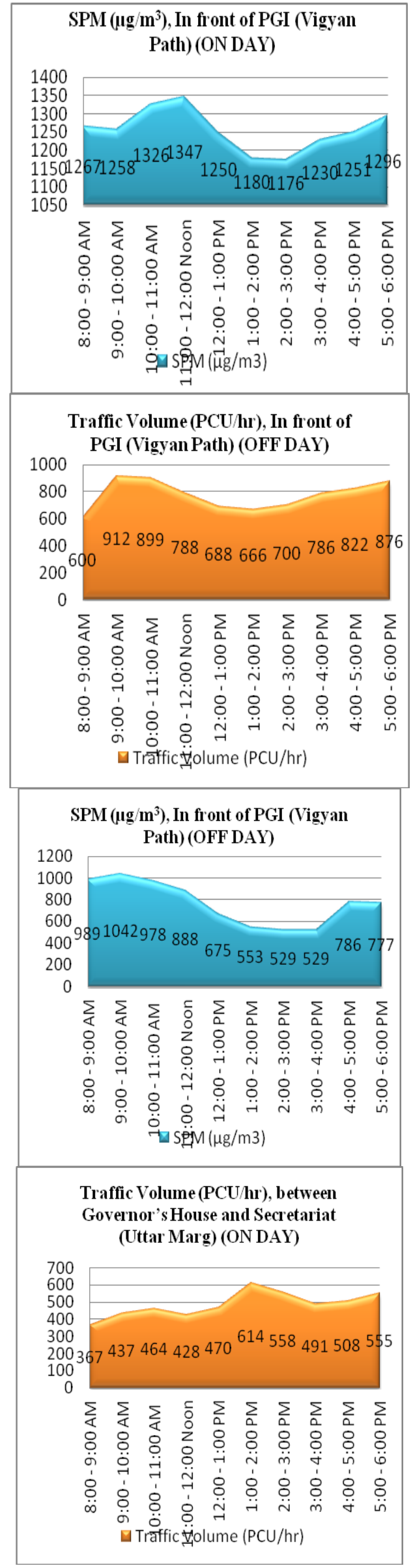

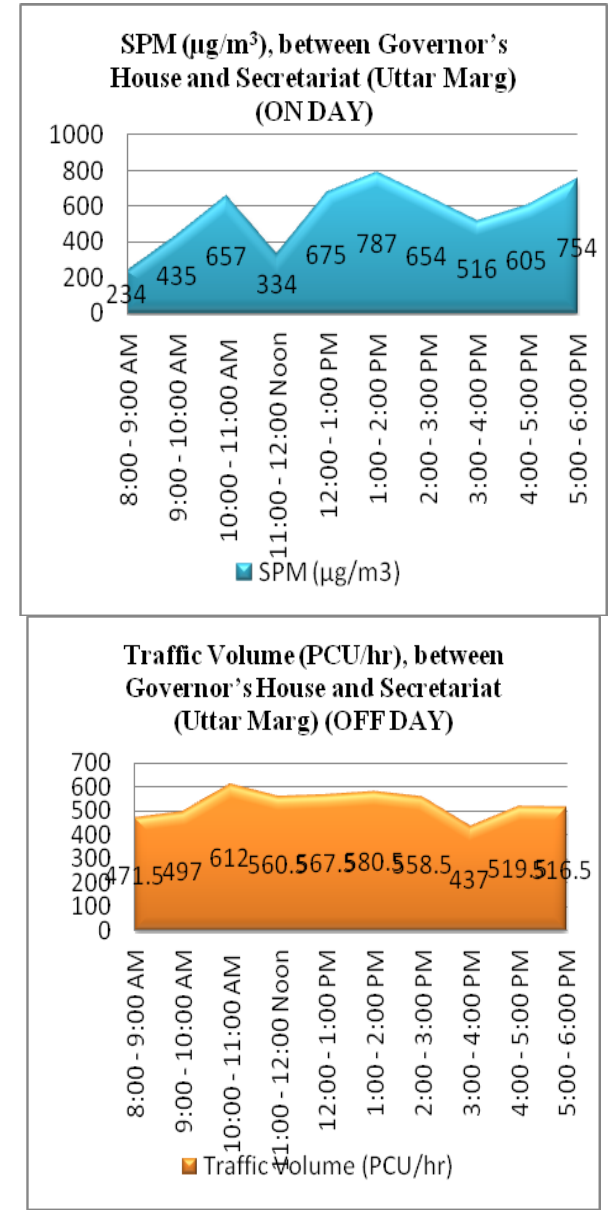

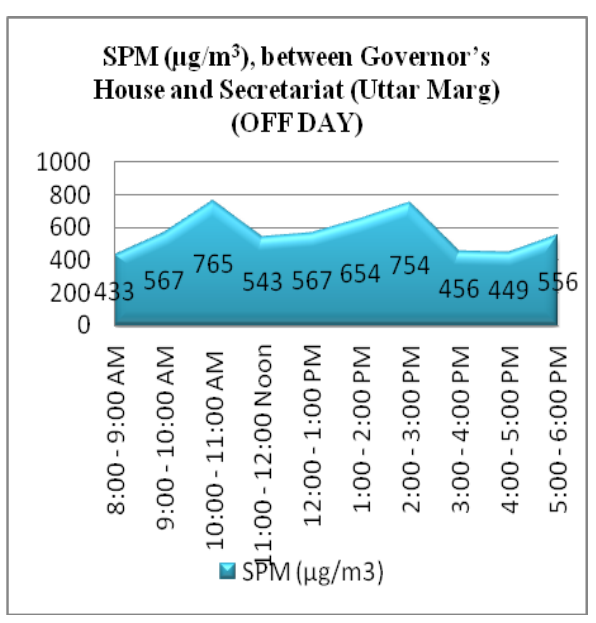

Fig. 2: Variation of SPM and Traffic volume During Study Hours of the Day

\section{ANALYSIS OF DATA}

\begin{tabular}{|l|c|c|c|c|}
\hline \multirow{2}{*}{ Road } & \multicolumn{2}{|c|}{ Max. S.P.M } & \multicolumn{2}{c|}{ Corresponding Traffic } \\
\cline { 2 - 5 } & $\begin{array}{c}\text { ON Day } \\
\text { (Average of } \\
\text { 5 Working } \\
\text { days) }\end{array}$ & $\begin{array}{c}\text { OFF Day } \\
\text { (Average of 2 } \\
\text { non-working } \\
\text { days) }\end{array}$ & $\begin{array}{c}\text { ON Day } \\
\text { (Average of } \\
\text { 5 Working } \\
\text { days) }\end{array}$ & $\begin{array}{c}\text { OFF Day } \\
\text { (Average of 2 } \\
\text { non-working } \\
\text { days) }\end{array}$ \\
\hline $\begin{array}{l}\text { Vigyan } \\
\text { Path }\end{array}$ & 1347 & 1042 & 998 & 912 \\
\hline $\begin{array}{l}\text { Uttar } \\
\text { Marg }\end{array}$ & 787 & 765 & 614 & 612 \\
\hline
\end{tabular}


1. The increase of traffic volume augments SPM concentration i.e. the maximum SPM concentration is recorded during the peak hour of traffic.

2. Even the minimum recorded value of the day is higher than the permitted limit at both the locations.

\section{REGRESSION ANALYSIS}

The purpose of the experimentation was to gauge the itinerary of SPM concentration. To find the variation in particulae matter, with the change in level of traffic volume. The outcome of the analysis is presented as liner regression equation, in table -2 below.

TABLE 2: REGRESSION MODEL FOR SPM CONCENTRATION

\begin{tabular}{|c|c|}
\hline Linear equation & $\mathrm{Y}=-0.0141 \mathrm{X}+239.893$ \\
\hline $\begin{array}{c}\text { Multiple ' } \mathrm{R} \text { ' } \\
\text { error }\end{array}$ & 0.005 \\
\hline $\mathrm{F}$-value & 164.411 \\
\hline $\mathrm{p}$ - value & 0.063 \\
\hline
\end{tabular}

\section{CONCLUSIONS AND RECOMMENDATIONS}

The concern of environment has become central to all the developmental activities worldwide. Most of the cities are facing serious Traffic Related SPM problems due to the increase of motor vehicles and human population within the confined urban areas. Even in the situation under consideration, the determined value of suspended particulate matter were found to be exceeding permissible limits in the residential zone posing a direct threat to the health of inhabitants causing asthma and various lungs disorders. Most of the suspended particulate matter along the roadside is due to the exhaust by traffic and dust on the road which is dispersed by the traffic. Suitable measures should be taken to keep a check on the emission levels of suspended particulate matter by vehicles and to maintain the roads and keep them dust free. Proper disposal of leaves and garbage lying on the roadside should be done. Efforts should be done to replace the existing dusty shoulders with the paved ones.

\section{REFERENCES}

[1] Vinish Kathuria, "Vehicular Pollution control in Delhi, India - Are the efforts enough?", The Beijer Institute, International Institute of Ecological Economics, The Royal Swedish Academy of Sciences, Stockholm,. Sweden, August, 2001.

[2] Sukla Bhaduri, “Vehicular Growth and Air Quality at Major Traffic Intersection Points in Kolkata City: An Efficient Intervention Strategies", The SIJ Transactions on Advances in Space Research \& Earth Exploration (ASREE), Vol. 1, No. 1, September-October 2013.

[3] IS 5182 (Part 4) 1999; Methods for Measurement of Air Pollution (Suspended Particulate Matter), Bureau of Indian Standard.

[4] IRC: 106-1990 "Guidelines for capacity of urban roads in plain areas Indian roads congress, New Delhi.

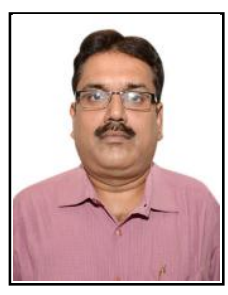

A. Dr. Umesh Sharma, is Associate Professor of Civil Engineering at PEC University of Technology (Formally, Punjab Engineering Collage), Chandigarh. $\mathrm{He}$ did his doctorate from PEC university of Technology. Dr Sharma has more than 25 years of academic and research experience, during which he authored more than 100 papers in journals, conferences and seminars. $\mathrm{He}$ is a member of Institution of Engineers (India), Indian Road congress, The institute of Urban Transport and Indian Society for Technical Education.

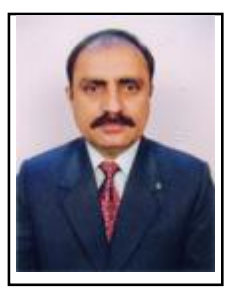

B.. Dr. S.N Sachdeva is Professor at N.I.T Kurukshetra, Haryana. His broad Area of Research is Transportation/ Highway Engg and his research interests are in Highway capacity (ii) Highway Materials and Road Safety.

Dr Sachdeva has more than 20 years of academic and research experience, during which he authored more than 40 papers in journals, conferences and seminars. He is a life member of IRC, ISTE, IUT and ISRMTT.

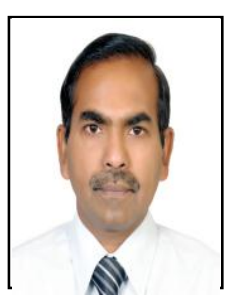

C. Dr. Siby John, is Professor and Head of Civil Engineering at PEC University of Technology (Formally, Punjab Engineering Collage), Chandigarh. He did his doctorate from IIT, Kanpur. Dr John has more than 30 years of academic and research experience, during which he authored more than 50 peer reviewed articles. He has contributed more than 100 papers in conferences and seminars. He has also authored two books on environmental pollution. He is a fellow of Institution of Engineers (India) and member of IAEM, ISTE and IAAPC 